\title{
Effectiveness of a brief versus a comprehensive social marketing program
}

$\underline{\text { Abstract }}$

Purpose - Gamified and engaging school-based alcohol social marketing programs have demonstrated effectiveness; however, wide-scale dissemination of these programs is limited by their resource-intensive character. To address this limitation, a brief alcohol social marketing pilot program was derived from a comprehensive alcohol social marketing program to compare effectiveness.

Design/methodology/approach - A sample of 115 14-16-year-old adolescents from six secondary schools participated in the brief alcohol social marketing pilot program. Program effectiveness was assessed using repeated measure analysis on adolescents' knowledge, attitudes, social norms, self-efficacy and intentions to binge drink. Results were compared with the comprehensive social marketing program and a control group.

Findings - The brief pilot program produced statistically significant outcomes for the same measures as the comprehensive program across attitudinal variables, descriptive norms and opportunistic self-efficacy.

Research limitations/implications - Converting existing social marketing programs into brief alternatives is more cost-effective and, in this case, demonstrated better outcome effects. However, findings are limited as in-depth comparisons were hindered by changes to content across program modes. No process for converting comprehensive programs into brief alternatives was identified prior to this study, and therefore a number of considerations for program alteration were derived from program facilitator experiences.

Originality/value - The findings provide initial evidence that a brief version of an existing comprehensive program can be an effective alternative to more resource-intensive programs under more cost-effective circumstances for program developers and facilitators.

Keywords - Brief program, comprehensive programs, school, alcohol

Paper type: Research paper 


\section{Background}

There is little scientific evidence of benefits from consuming alcohol (Arranz et al., 2012), especially that which exceeds the potential for damage caused by its consumption (Rehm et al., 2010). Yet despite evidence demonstrating alcohol's harmful impacts on health and wellbeing (Hall et al., 2016, Rehm et al., 2009), consumption of high amounts of alcohol is often glorified rather than discouraged (Russell-Bennett and Golledge, 2009). Alcohol holds strong cultural significance (WHO, 2018), and its consumption is associated by young people with maturity and pleasure (McCreanor et al., 2005). Therefore, between severe health consequences (McClure et al., 2016), psycho-social consequences (Hall et al., 2016, Hicks et al., 2010) and the pervasiveness of alcohol advertising (Jones and Magee, 2011, Lobstein et al., 2017, Noel et al., 2017), it is clear why alcohol consumption, particularly binge drinking, retains a major public health focus in Australia and globally (Australian Government Department of Health, 2017, WHO, 2014, WHO, 2018).

In Australia adolescent populations have been identified as particularly at risk to the harms of binge drinking (Department of Health, 2015). Research suggests that adolescent drinking, particularly binge drinking, is a necessary risk factor to address in preventing problems surfacing during adulthood, such as drug use, alcohol dependency and criminal activity (Hawkins et al., 1992, Maggs et al., 2008, Marmorstein, 2009). In recent years, alcohol has been classified as a 'major contributor' to burden of disease in adolescents (AIHW, 2016, AIHW, 2019), contributing to $22 \%$ of burden due to road traffic injuries, and $14 \%$ of burden relating to suicide and/or self-injury (AIHW, 2019). Consequently, school-based prevention programs have been the most frequently adopted approach to reducing alcohol's impact on adolescent populations (Foxcroft and Tsertsvadze, 2012, Lee et al., 2016). These programs typically attempt to transfer knowledge of harms and provide strategies to make responsible decisions regarding alcohol (Lee et al., 2016, Rundle-Thiele et al., 2015). It has been observed however that effectiveness of school-based alcohol prevention or intervention programs is dependent on more than simply knowledge (Lemstra et al., 2010), and subsequently the overall effectiveness of school-based programs is mixed (Onrust et al., 2016). School-based approaches are often delivered in a didactic and teacher-focussed manner and are largely facilitated by teachers who may be underprepared or dislike delivering alcohol education to students (Tupper, 2008). Such programs lack student engagement (Shernoff et al., 2003), emphasise knowledge transfer over considerations such as interactivity (Lee et al., 2016, 
Onrust et al., 2016), and ultimately the effectiveness of programs is hindered (Shernoff et al., 2017, Tobler et al., 2000).

In an attempt to address these limitations, contemporary efforts of alcohol prevention programs have appropriately focussed on student engagement and fun through the use of interactivity, gamification and digital technologies (Dietrich et al., 2019, Durl et al., 2018, Teesson et al., 2017). These program characteristics have been adopted in social marketing programs, as this approach lends itself well to social marketing's focus on influencing individual and community behaviour for social good (ISMA, 2013). A recent example of this approach in social marketing is the 'Blurred Minds' program (Dietrich et al., 2019), wherein a series of online games, discussions, interactive activities and a Virtual Reality house party were used to communicate five distinct lessons surrounding alcohol. Displaying promising change outcomes in its most recent iterations, 'Blurred Minds' adopted an 'improve rather than prove' perspective (Gordon and Gurrieri, 2014) in order to refine program deliveries to better prevent adolescent alcohol consumption. The current study feeds into this agenda in three ways. First, relevant literature was explored to compare the program's current approach to content development (i.e., comprehensive skills training), with an appropriate mode alternative (i.e., brief alcohol education). Secondly, the methodology outlines how the pilot program was altered from a comprehensive version to a brief alternative. Finally, a comparative assessment of the pilot program against the comprehensive program and a control group is presented and discussed. The results of this comparative assessment justify process considerations that allow for developing more resource-effective programs. 


\section{Literature Review}

\section{Comprehensive programs}

Comprehensive programs (sometimes referred to as Comprehensive life skills programs, or 'CLS') represent a shift from traditional alcohol education efforts that relied on knowledge transfer, to providing coping and resilience strategies when faced with drinking opportunities (Lee et al., 2016). The value of training students psychosocial skills is that these skills would often be transferrable to other risk situations outside of alcohol consumption (Lee et al., 2016). Reviews have framed 'comprehensive' as an approach to content development, and that a program could be considered comprehensive if for example anti-drug information with refusal skills training, social skills training and self-management skills were included (Lemstra et al., 2010). Yet, a clear scope around what constitutes a 'comprehensive' program remains underexplored in the literature. In practice, comprehensive alcohol programs targeting young consumers are resource-intensive and require trained facilitators (Botvin et al., 2003), multiple sessions often being delivered over an entire term or even multiple years (Spaeth et al., 2010), and - in school settings - necessitate the involvement of teachers (McBride et al., 2004). While comprehensive school-based programs involve interactivity and discussion - signs of effective and engaging school-based programs (Baron and Corbin, 2012) - the complexity and length of many programs and their materials along with extensive teacher training hinder implementation fidelity. As a result schools are hesitant to adopt such programs into their curriculum (McBride et al., 2004, Vogl et al., 2012). In lieu of changing the type of content delivered in school-based programs, delivery modes that are less resourceintensive while also addressing implementation fidelity and student engagement, and subsequently change outcomes, deserve more consideration (Shernoff et al., 2016).

\section{Brief programs}

In light of limited access issues and time constraints faced by students, schools and program facilitators, brief programs have been identified as a priority within the Australian national drug strategy (Australian Government Department of Health, 2017). Brief programs are considered to be therapeutic or preventive programs undertaken in a short duration and generally with healthcare professionals (Aalto et al., 2001). Brief program outcomes tend to focus on reducing alcohol consumption, and providing skills to either maintain abstinence or regulate behaviour related to alcohol consumption (Babor et al., 2007, Dunn et al., 2001, Rollnick and Miller, 1995). These programs are positioned to support practices such as training refusal skills and providing education on alcohol harms for health, while also 
addressing concerns of disengagement and information overload. Between skills training and an emphasis on shorter, more direct engagements with participants, brief programs could be positioned as a suitable evolution from typical comprehensive programs that face too many implementation barriers in a school setting. Brief programs can be conducted individually or in a group setting, and typically run anywhere between 15-120 minutes (Vasilaki et al., 2006), with exceptions reporting up to five hours in length (Hennessy and Tanner-Smith, 2015). Inconsistencies are evident when assessing time considerations for brief programs, suggesting that consensus amongst researchers and experts is still lacking.

Brief alcohol programs have generally been approached from two broad research areas: clinical psychology and school-based education. From the clinical psychology perspective, brief programs take the form of screening, referral and/or counselling for participants (Terlecki et al., 2015). These programs are mostly delivered to individuals in a face-to-face setting (Carney et al., 2016), to participants in primary care settings (Heather, 2014, Kaner et al., 2013, McCambridge and Rollnick, 2014) or following a breach in conduct (e.g., disciplinary action in college or university) (Terlecki et al., 2015). Generally, the focus of these programs is to reduce or end consumption of alcohol, rather than preventing onset or increased consumption amongst adolescents. Mixed results in primary care have been observed however, despite showcasing some reductions in alcohol consumption (Kaner et al., 2013), supporting calls for further investigation into the influence of a brief delivery mode on program outcomes (McCambridge and Rollnick, 2014)

Whether a brief program is intended as an intervention or prevention tool, programs are typically directed to individuals rather than groups, however group deliveries have been documented with some promising results in school-based contexts (Carney et al., 2016). Further, participants are empowered and encouraged in their change efforts rather than simply told what to do, therefore laying the foundation for further change efforts outside of alcohol and its consumption (Miller and Rollnick, 2012). This is arguably different to many comprehensive programs that seek to communicate life skills training to reduce or prevent alcohol consumption in the long term (Spaeth et al., 2010). Inconsistent and overlapping terminology associated with brief and comprehensive programs warrants investigation into where similarities and differences lay.

\section{Brief vs. comprehensive programs in school settings}

It is unwarranted to consider brief programs as entirely distinct from comprehensive ones, when considering the various overlapping qualities between the two, and the sometimes- 
inconsistent understanding of what 'brief' means in alcohol intervention contexts (see Table 1). Yet, comprehensive and brief programs conducted in a school-based context can still vary substantially. For instance, brief programs delivered to adolescents have typically incorporated screening and referral, wherein comprehensive program deliveries emphasised education and skills-transfer (Botvin et al., 2003, Conrod et al., 2013). Importantly, effective brief programs have addressed factors influencing onset of alcohol consumption as a coping mechanism, rather than instructing participants on why and how to stop drinking (Conrod et al., 2013). Alongside the short time-frame required to deliver a brief program, these deliveries are likely to be less resource-intensive compared to typical comprehensive school-based alcohol programs (Hennessy and Tanner-Smith, 2015, McBride et al., 2004).

\section{Insert Table 1 here}

It is not necessary however for brief programs to avoid education, nor do comprehensive programs necessitate alcohol avoidance strategies instead of addressing underlying factors to drinking. Further, there have yet been no comparisons made between school-based alcohol social marketing programs delivered in a 'brief' versus a 'comprehensive' fashion, likely due to overlapping and indistinct characteristics they share. Given issues such as resource intensity typically associated with comprehensive school-based programs, it is surprising that researchers have not attempted to develop and document how a brief program could be developed based on an established comprehensive version. While characteristics between program types vary, there is merit in examining components typical of both intervention types (e.g., group deliveries, skills training) while also adopting the key merits of brief interventions (e.g., short-time and cost-efficiency). To address this gap, this study has a two-fold aim: 1) Derive a brief pilot program from an effective comprehensive social marketing program, and, 2) Assess and compare the effectiveness of the brief pilot versus the original comprehensive program. The following research question guided this study:

Are positive outcomes from a comprehensive school-based alcohol social marketing program maintained when delivered in a brief program pilot? 


\section{Method}

The 'Blurred Minds' alcohol program is a comprehensive school-based social marketing program which was built on the theory of gamified learning (Landers, 2014) and social cognitive theory (Bandura, 1989). The program features a range of games, activities and discussions to provide a variety of alcohol-related lessons, including but not limited to providing peer refusal skills and knowledge about alcohol harms. The comprehensive program version demonstrated positive effects (Dietrich et al., 2019) and was well-received by the primary funding partner (Queensland Catholic Education Commission, Australia) and other important stakeholders, including schools and teachers. Despite the positive reception however, the 'Blurred Minds' program still faces barriers to uptake when enquiring with new schools. This has generally been due to the comprehensive nature of the program featuring five lessons which can be delivered in a full day or throughout a school term. Schools are hesitant to take up new and seemingly time-intensive and costly programs. Costs for outsourcing are often high and the majority of schools ultimately do not have the funds to engage external providers (Williams et al., 2011) unless programs are more affordable. To increase the uptake of 'Blurred Minds' by schools, a less resource-intensive and more effective delivery mode was sought, resulting in the development of the brief 'Blurred Minds' pilot program (see Table 2). The next section outlines the development of the brief program.

\section{Insert table 2 here}

\section{Brief program development process}

The brief pilot program of the current study derived lesson content from the existing comprehensive 'Blurred Minds' program which originally included five lessons: 1) Experience effects 2) Science of alcohol, 3) Myths and norms, 4) Legalities, and 5) Resilience. All five original lessons were carefully considered to inform the development of the brief pilot program. It is important to highlight that this process was guided by rich previous experience from the research team that had delivered the comprehensive program to thousands of students over the lifetime of the project (Dietrich et al., 2019, Dietrich et al., 2015, Rundle-Thiele et al., 2013). A content inventory was conducted to formally identify program components to take out or to remain in the new program iteration. Consequently, the content of the five lessons were disassembled according to how the program was delivered, and then reassembled to produce six new lesson categories (Yin, 2011, Yin, 2015). These refined lessons included 1) Alcohol Marketing, 2) BAC \& Standard Drinks, 3) Drugs \& Addiction, 4) Legalities, 5) Alcohol \& the Brain, and 6) Moderation \& Refusal Strategies. Of 
these six, 'Legalities' included content relating to each of the other five lessons and was subsequently removed with content collapsed across other lessons.

\section{Insert table 3 here}

Each lesson was originally designed to be engaging as well as informative, featuring both online and offline games and activities, such as trivia, back and forth discussions between facilitators and students, videos, group activities, and a Virtual Reality (VR) 'house-party simulation' (Dietrich et al., 2019). After refining the program into a brief alternative, the program ran for a total of 100 minutes, falling within the length of previous brief programs (Vasilaki et al., 2006). As resource-intensiveness was a key consideration for the adaptation to a brief delivery format, group deliveries were utilised to reach the most students in few deliveries.

\section{Measures}

The evaluations of the comprehensive and brief 'Blurred Minds' programs were guided by the Theory of Planned Behaviour (Ajzen, 1991), utilising measures adopted in the comprehensive program iteration (see Dietrich et al., 2019, Rundle-Thiele et al., 2015). The pre-post questionnaire included measures such as attitudes towards drinking alcohol (Rivis and Sheeran, 2013), intentions to drink alcohol (Fishbein and Ajzen, 2010), social norms surrounding drinking (Norman and Conner, 2006), and self-efficacy to refuse drinking when offered alcohol (Patton et al., 2018). Scales for these outcome variables have been utilised previously in published studies exploring similar topics/contexts (Patton et al., 2018) and were previously validated (Norman and Conner, 2006, Rivis and Sheeran, 2013, RundleThiele et al., 2015) as well as determined to be reliable scales according to convention (Neuman, 2013). Socio-demographic characteristics such as date of birth, gender, school attending, and country of origin were included, along with behavioural questions regarding current drinking and AUDIT (Alcohol use disorders identification test) questions (WHO, 2006). Satisfaction with activities and games from the program were drawn from previous 'Blurred Minds' iterations (Rundle-Thiele et al., 2013). Differences between pre- and postsurvey measurement were determined through paired sample t-tests (SPSS version 25). 


\section{Analysis}

This brief pilot program ran concurrently with the 2015-2018 cluster randomised controlled trial of the comprehensive 'Blurred Minds' program. This study adopts a repeated measures design in order to compare outcome effects with previously collected data of the larger randomised controlled trial (Dietrich et al., 2019). Findings were derived from brief pilot program deliveries in six schools $(n=115)$ across two Australian states. These findings are contrasted against the results from schools, involving both intervention and control schools, featured in the larger randomised controlled trial of the comprehensive program $(n=336)$, delivered to schools in Queensland. Simple slopes analysis was conducted in order to identify and explore possible interaction effects between the independent variables measured (i.e., attitudes, self-efficacy and social norms) and program modality (i.e., comprehensive vs. brief pilot).

The target population for this study was 14-16-year-olds, the same age group targeted for the comprehensive program trial. The primary recruitment method for acquiring the sample was school-based recruiting, wherein a combination of previous partner schools from the comprehensive program trial and new school contacts were offered a place in the brief pilot program trial. Contacts at each school were offered a free delivery of the brief pilot program, in exchange for data collection with participating students. This study was approved by the University's Human Research Ethics Committee (Ref No: 2016/086), and informed consent was gained from each participant prior to partaking in the program. 


\section{Results}

\section{Sample characteristics}

All participants across programs were between 14 and 16 years of age. Eighty-one percent of brief program participants indicated they consumed alcohol, a similar proportion to the comprehensive program sample, with seventy-three percent of participants stating that they consumed alcohol. The majority of both the brief (seventy-eight percent) and comprehensive (eighty-six percent) program participants stated that they consumed alcohol at least monthly, with many declaring more frequent drinking behaviour in each sample group. In both samples, almost half of participants indicated that when drinking, they consumed six or more standard drinks at least monthly (fifty-eight and fifty-six for the comprehensive and brief program samples respectively).

\section{Insert table 5 here}

\section{Program effectiveness}

Table 6 presents results from pre- and post-program evaluations from the brief and comprehensive social marketing programs and a control group. Experiential attitudes among the brief program participants were significantly more negative in the post-survey than in the pre-survey $\mathrm{t}(114)=2.13, \mathrm{p}<0.05$. Similarly, instrumental attitudes were more negative following the brief program than before $\mathrm{t}(114)=3.63, \mathrm{p}<0.001$. Descriptive norms towards binge drinking were less favourable after brief program participation $t(111)=2.44, p<0.05$. Opportunistic self-efficacy was significantly improved following the brief program delivery compared to the pre-survey $\mathrm{t}(111)=-7.16, \mathrm{p}<0.001$. No significant changes in intentions to drink were observed in the samples.

\section{Insert table 6 here}

For comparison, the comprehensive program demonstrated improvements for participants experiential attitudes $\mathrm{t}(335)=6.334 \mathrm{p}<0.001$, instrumental attitudes $\mathrm{t}(335)=4.271, \mathrm{p}<0.001$ and descriptive norms $\mathrm{t}(330)=2.407, \mathrm{p}<0.05$. In contrast to the brief social marketing program, opportunistic self-efficacy among participants in the comprehensive condition decreased following program participation $\mathrm{t}(319)=3.624, \mathrm{p}<0.001$.

The control condition demonstrated worsened experiential attitudes $t(367)=2.316, p<0.05$, injunctive norms $\mathrm{t}(359)=-3.317, \mathrm{p}<0.001$, and opportunistic self-efficacy $\mathrm{t}(357)=3.697$, $\mathrm{p}<0.001$. Further, the participants in the control condition also demonstrated a significant increase in intention to consume alcohol $\mathrm{t}(366)=-2.309, \mathrm{p}<0.05$. 
The results of the t-test showed that the effects of the comprehensive program were seemingly replicable in the brief alternative. To further explore the nature of the effect of modalities on outcomes, simple slopes analysis was conducted, wherein program modality was used as a moderator for the relationships between attitudes, self-efficacy and social norms, and intentions. When attitudes, social norms and self-efficacy was moderated by program modality, there was a significant interaction effect observed only between social norms and program modality $(\beta 0.224, \mathrm{p}=0.002)$. High levels of social norms (one standard deviation above the mean) and low levels of social norms (one standard deviation below the mean) where used to further explore the moderating effect of program modality, however no significant was observed.

\section{Insert table 7 here}

\section{Program satisfaction}

Participants stated they were 'somewhat satisfied' or 'very satisfied' with each of the online and offline activities included in the brief pilot program, with none receiving a majority of dissatisfied or very dissatisfied responses. On a 5-point Likert scale, participants ranked the VR house party simulation first amongst the online activities, followed by 'Perfect pour', 'Deso driver', 'Alcohol trivia show' and finally the 'Bar master'. The alcohol trivia show was ranked higher than both 'Perfect pour' and 'Deso driver' in the comprehensive program condition. Participants ranked 'Power of marketing' and 'Keeping it classy' highest, followed by the 'Myth-busting and norms' session. These rankings again differ from the comprehensive program, as 'Power of marketing' was not ranked as highly as 'Keeping it classy' previously. As the brief program condition removed/redistributed content from the comprehensive program delivery, not all activities could be compared by their satisfaction scores. These included activities such as the 'BACToZero' game, and the 'Legal Q\&A' (see Table 3). 


\section{Discussion}

This paper attempted to establish whether positive outcomes from a comprehensive schoolbased alcohol social marketing program can be maintained when delivered in a brief pilot program, and had a two-fold aim: 1) Derive a brief pilot program from an effective comprehensive social marketing program, and, 2) Assess and compare the effectiveness of the brief pilot versus the original comprehensive program. The results are discussed hereafter beginning with a reflection on the design of the brief pilot program in conjunctions with contributions for the social marketing theory and practice. In line with the comprehensive program, brief pilot program participants held more negative attitudes towards drinking and less favourable descriptive norms, characterised by less favourable views towards normative drinking perceptions, between pre and post observation. Social norms serve as competing forces or barriers to abstaining from drinking (Kirby et al., 2008) and the effects of the brief program are therefore encouraging. Importantly, both the comprehensive and brief treatment arms demonstrated positive results (e.g., less favourable attitudes towards drinking), while the results of the control participants showed unfavourable results (e.g., higher intention to consume alcohol between pre and post). Interaction effects were explored between the program modalities and each independent variable, with an impact of program modality on social norms being observed. While this interaction implies that different program dosages may somewhat influence participants normative perceptions of alcohol, it does not suggest sizeable differences between program modalities. This research therefore indicates that changing a comprehensive program into a brief alternative did not hinder the program's effectiveness. This is particularly interesting and relevant as it shows that similar effects can be achieved with less resources being invested into program delivery (Hennessy and TannerSmith, 2015, McBride et al., 2004). This is also a promising outcome when compared to contexts such as primary care, wherein limited evidence exists showcasing brief programs positive influence on program outcomes (Kaner et al., 2013, McCambridge and Rollnick, 2014).

In contrast to the results of the comprehensive program, the brief pilot program produced a significant increase in opportunistic self-efficacy. This increase was somewhat surprising when considering the unintended decrease observed in the comprehensive program (Dietrich et al., 2019). An increase or decrease in this construct may be the result of participants adjusting their perceptions of their abilities to refuse alcohol offerings in social settings when facing peer pressure (Ding et al., 2018). Whilst this does not explain why the brief pilot 
program was able to increase participants opportunistic self-efficacy to refuse alcohol, it does however offer merit for using a brief delivery mode for delivering existing, comprehensive alcohol content, feeding into a broader aim of social marketing programs to be reiterative and improve over time (Gordon and Gurrieri, 2014).

\section{Limitations and future research}

While results from delivering the brief pilot program were positive, it is important to consider that no existing process was identified prior to this study that outlined how to convert a comprehensive program into a brief program version. This meant that changes between programs were largely made by the discretion of the research team as designers and facilitators of the comprehensive program. Reflecting on the development and evaluation of the brief pilot program, a set of focal areas for future research emerged as important to the process of converting comprehensive programs into brief alternatives. These include duration of the program, knowledge translation in content redevelopment, stakeholder involvement, theory use, experience of the facilitators, and delivery platform. These considerations broadly cover the decisions made by the research team to transition the comprehensive program into a more resource effective alternative, without sacrificing key themes, content and lesson outcomes. Said considerations could subsequently be examined in future research as potential criteria for brief program development.

In order to change the comprehensive program into a brief version, some content was removed, rearranged or shortened, potentially confounding the comparisons of the two program modalities. However, the current study sought to contrast two programs differing by duration, to determine if positive change outcomes could be replicated in a shorter and lessresource efficient delivery mode. This suggests that a pre-post comparison of each program was the most suitable choice in the current research design. Moving forward, a 'most-similar' comparison analyses of standalone programs, rather than iterations between delivery modes, would produce more generalisable results and substantiate the efficacy of brief programs as alternatives in other problem contexts (Esser and Vliegenthart, 2017).

Individual program components were not assessed in terms of program outcomes in either the comprehensive or brief program iterations. This limits interpretations of results regarding individual activities (e.g., VR's impact on self-efficacy to refuse alcohol). This lack of data prevents selection of program components from the comprehensive program to retain in the brief pilot alternative beyond user satisfaction ratings, teacher feedback and facilitator experience from previous program deliveries. The adapted brief program somewhat 
overcomes this by retaining the majority of activities and the key themes, content and lesson outcomes from the comprehensive program. Assessing the effectiveness of individual components on different outcome measures is therefore warranted.

\section{Conclusion}

The current study sought to determine whether an effective comprehensive social marketing program could be converted into a shorter and less resource intensive brief delivery format. The findings indicate that converting a comprehensive social marketing program into a brief alternative is feasible, considering that shorter delivery times and less resources used provided superior outcomes to the comprehensive program version. Although the brief program developed in this research is merely a pilot, the process undertaken in the current study provide a stronger basis for converting comprehensive programs into brief alternatives, regardless of context. 


\section{Reference List}

AALTO, M., SEPPÄ, K., MATTILA, P., MUSTONEN, H., RUUTH, K., HYVÄRINEN, H., PULKKINEN, H., ALHO, H. \& SILLANAUKEE, P. 2001. Brief intervention for male heavy drinkers in routine general practice: a three-year randomized controlled study. Alcohol and Alcoholism, 36, 224-230.

AIHW 2016. Trends in alcohol availability, use and treatment 2003-04 to 2014-15. In: AIHW (ed.). Canberra, Australia.

AIHW 2019. Australian Burden of Disease Study: impact and causes of illness and death in Australia 2015. Canberra: AIHW.

AJZEN, I. 1991. The Theory of Planned Behaviour. Organizational Behavior and Human Decision Process, 50, 179-211.

ARRANZ , S., CHIVA-BLANCH, G., VALDERAS-MARTÍNEZ, P., MEDINA-REMÓN, A., LAMUELA-RAVENTÓS, R. M. \& ESTRUCH, R. 2012. Wine, beer, alcohol and polyphenols on cardiovascular disease and cancer. Nutrients, 4, 759-781.

AUSTRALIAN GOVERNMENT DEPARTMENT OF HEALTH 2017. National drug strategy 2017-2026. In: HEALTH, D. O. (ed.).

BABOR, T. F., MCREE, B. G., KASSEBAUM, P. A., GRIMALDI, P. L., AHMED, K. \& BRAY, J. 2007. Screening, Brief Intervention, and Referral to Treatment (SBIRT). Toward a public health approach to the management of substance abuse. Substance abuse, 28, 7-30.

BANDURA, A. 1989. Social cognitive theory. , Greenwich, CT, JAI Press.

BARON, P. \& CORBIN, L. 2012. Student engagement: rhetoric and reality. Higher Education Research \& Development, 31, 759-772.

BOTVIN, G. J., GRIFFIN, K. W., PAUL, E. \& MACAULAY, A. P. 2003. Preventing tobacco and alcohol use among elementary school students through life skills training. Journal of Child \& Adolescent Substance Abuse, 12, 1-17.

CARNEY, T., MYERS, B. J., LOUW, J. \& OKWUNDU, C. I. 2016. Brief school-based interventions and behavioural outcomes for substance-using adolescents. Cochrane Database Syst Rev, 2016, CD008969.

CONROD, P. J., O’LEARY-BARRETT, M., NEWTON, N., TOPPER, L., CASTELLANOSRYAN, N., MACKIE, C. \& GIRARD, A. 2013. Effectiveness of a selective, personality-targeted prevention program for adolescent alcohol use and misuse: A cluster randomized controlled trial. JAMA Psychiatry, 70, 334-342.

DEPARTMENT OF HEALTH. 2015. Alcohol [Online]. Available: http://www.alcohol.gov.au/internet/alcohol/publishing.nsf/Content/home [Accessed].

DIETRICH, T., RUNDLE-THIELE, S., KUBACKI, K., DURL, J., GULLO, M., ARLI, D. \& CONNOR, J. P. 2019. Virtual Reality in Social Marketing: A Process Evaluation. Marketing Intelligence and Planning.

DIETRICH, T., RUNDLE-THIELE, S., SCHUSTER, L., DRENNAN, J., RUSSELLBENNETT, R., LEO, C., GULLO, M. J. \& CONNOR, J. P. 2015. Differential segmentation responses to an alcohol social marketing program. Addict Behav, 49, 6877. 
DING, L., NEWMAN, I. M., BUHS, E. S. \& SHELL, D. F. 2018. Influence of Peer Pressure and Self-efficacy for Alcohol Self-Regulation on Chinese University Physical Education Students' Drinking Behaviours. Advances in Physical Education, 8, 46-57.

DUNN, C., DEROO, L. \& RIVARA, F. P. 2001. The use of brief interventions adapted from motivational interviewing across behavioral domains: a systematic review. Addiction, 96, 1725-1742.

DURL, J., DIETRICH, T., PANG, B., POTTER, L.-E. \& CARTER, L. 2018. Utilising virtual reality in alcohol studies: A systematic review. Health Education Journal, 77, 212225.

ESSER, F. \& VLIEGENTHART, R. 2017. Comparative research methods. The International Encyclopedia of Communication Research Methods.

FISHBEIN, M. \& AJZEN, I. 2010. Predicting and changing behavior: The reasoned action approach, New York, NY, Psychology Press.

FOXCROFT, D. R. \& TSERTSVADZE, A. 2012. Universal alcohol misuse prevention programmes for children and adolescents: Cochrane systematic reviews. Perspect Public Health, 132, 128-34.

GORDON, R. \& GURRIERI, L. 2014. Towards a reflexive turn: social marketing assemblages. Journal of Social Marketing, 4, 261-278.

HALL, W. D., PATTON, G., STOCKINGS, E., WEIER, M., LYNSKEY, M., MORLEY, K. I. \& DEGENHARDT, L. 2016. Why young people's substance use matters for global health. The Lancet Psychiatry, 3, 265-279.

HAWKINS, J. D., CATALANO, R. F. \& MILLER, J. Y. 1992. Risk and protective factors for alcohol and other drug problems in adolescence and early adulthood: implications for substance abuse prevention. Psychological bulletin, 112, 64.

HEATHER, N. 2014. Interpreting null findings from trials of alcohol brief interventions. Front Psychiatry, 5, 85.

HENNESSY, E. A. \& TANNER-SMITH, E. E. 2015. Effectiveness of Brief School-Based Interventions for Adolescents: A Meta-analysis of Alcohol Use Prevention Programs. Prevention Science, 16, 463-474.

HICKS, B. M., IACONO, W. G. \& MCGUE, M. 2010. Consequences of an adolescent onset and persistent course of alcohol dependence in men: adolescent risk factors and adult outcomes. Alcoholism: Clinical and Experimental Research, 34, 819-833.

ISMA. 2013. Consensus definition of Social Marketing [Online]. Available: https://www.isocialmarketing.org/assets/social_marketing_definition.pdf [Accessed].

JONES, S. C. \& MAGEE, C. A. 2011. Exposure to Alcohol Advertising and Alcohol Consumption among Australian Adolescents. Alcohol and Alcoholism, 46, 630-637.

KANER, E. F., BLAND, M., CASSIDY, P., COULTON, S., DALE, V., DELUCA, P., GILVARRY, E., GODFREY, C., HEATHER, N., MYLES, J., NEWBURY-BIRCH, D., OYEFESO, A., PARROTT, S., PERRYMAN, K., PHILLIPS, T., SHEPHERD, J. \& DRUMMOND, C. 2013. Effectiveness of screening and brief alcohol intervention in primary care (SIPS trial): pragmatic cluster randomised controlled trial. $B M J$ : British Medical Journal, 346, e8501.

KIRBY, J., VAN DER SLUIJS, W. \& INCHLEY, J. 2008. Young People and Substance use The influence of presonal, social and environmental factors on substance use among 
adolescents in Scotland. Child and Adolescent Health Research Unit, University of Edinburgh.

LANDERS, R. 2014. Developing a Theory of Gamified Learning: Linking Serious Games and Gamification of Learning. Simulation \& Gaming, 45, 752-768.

LEE, N. K., CAMERON, J., BATTAMS, S. \& ROCHE, A. 2016. What works in schoolbased alcohol education: A systematic review. Health Education Journal, 75, 780798.

LEMSTRA, M., BENNETT, N., NANNAPANENI, U., NEUDORF, C., WARREN, L., KERSHAW, T. \& SCOTT, C. 2010. A systematic review of school-based marijuana and alcohol prevention programs targeting adolescents aged 10-15. Addiction Research \& Theory, 18, 84-96.

LOBSTEIN, T., LANDON, J., THORNTON, N. \& JERNIGAN, D. H. 2017. The commercial use of digital media to market alcohol products: a narrative review. Addiction, 112, 21-27.

MAGGS, J. L., PATRICK, M. E. \& FEINSTEIN, L. 2008. Childhood and adolescent predictors of alcohol use and problems in adolescence and adulthood in the National Child Development Study. Addiction, 103, 7-22.

MARMORSTEIN, N. R. 2009. Longitudinal associations between alcohol problems and depressive symptoms: early adolescence through early adulthood. Alcoholism: Clinical and Experimental Research, 33, 49-59.

MCBRIDE, N., FARRINGDON, F., MIDFORD, R., MEULENERS, L. \& PHILLIPS, M. 2004. Harm minimization in school drug education: final results of the School Health and Alcohol Harm Reduction Project (SHAHRP). Addiction, 99, 278-291.

MCCAMBRIDGE, J. \& ROLLNICK, S. 2014. Should brief interventions in primary care address alcohol problems more strongly? Addiction, 109, 1054-1058.

MCCLURE, A. C., TANSKI, S. E., LI, Z., JACKSON, K., MORGENSTERN, M., LI, Z. \& SARGENT, J. D. 2016. Internet alcohol marketing and underage alcohol use. Pediatrics, 137, e20152149.

MCCREANOR, T., GREENAWAY, A., MOEWAKA BARNES, H., BORELL, S. \& GREGORY, A. 2005. Youth identity formation and contemporary alcohol marketing. Critical Public Health, 15, 251-262.

MILLER, W. R. \& ROLLNICK, S. 2012. Motivational interviewing: Helping people change, Guilford press.

NEUMAN, W. L. 2013. Social research methods: Qualitative and quantitative approaches, Pearson education.

NOEL, J. K., BABOR, T. F. \& ROBAINA, K. 2017. Industry self-regulation of alcohol marketing: a systematic review of content and exposure research. Addiction, 112, 2850.

NORMAN, P. \& CONNER, M. 2006. The theory of planned behaviour and binge drinking: Assessing the moderating role of past behaviour within the theory of planned behaviour. British Journal of Health Psychology, 11, 55-70.

ONRUST, S. A., OTTEN, R., LAMMERS, J. \& SMIT, F. 2016. School-based programmes to reduce and prevent substance use in different age groups: What works for whom? 
Systematic review and meta-regression analysis. CLINICAL PSYCHOLOGY REVIEW, 44, 45-59.

PATTON, K., CONNOR, J. P., RUNDlE-THIELE, S., DIETRICH, T., YOUNG, R. \& GULLO, M. J. 2018. Measuring adolescent drinking-refusal self-efficacy: Development and validation of the Drinking Refusal Self-Efficacy QuestionnaireShortened Adolescent version (DRSEQ-SRA). Addictive Behaviors, 81, 70-77.

REHM, J., BALIUNAS, D., BORGES, G. L., GRAHAM, K., IRVING, H., KEHOE, T., PARRY, C. D., PATRA, J., POPOVA, S., POZNYAK, V., ROERECKE, M., ROOM, R., SAMOKHVALOV, A. V. \& ROERECKE, M. 2010. The relation between different dimensions of alcohol consumption and burden of disease: an overview. Addiction, 105, 817-843.

REHM, J., MATHERS, C., POPOVA, S., THAVORNCHAROENSAP, M., TEERAWATTANANON, Y. \& PATRA, J. 2009. Global burden of disease and injury and economic cost attributable to alcohol use and alcohol-use disorders. The Lancet, 373, 2223-2233.

RIVIS, A. \& SHEERAN, P. 2013. Automatic risk behavior: Direct effects of binge drinker stereotypes on drinking behavior. Health Psychology, 32, 571.

ROLLNICK, S. \& MILLER, W. R. 1995. What is Motivational Interviewing?

RUNDLE-THIELE, S., RUSSELL-BENNETT, R., LEO, C. \& DIETRICH, T. 2013. Moderating teen drinking: combining social marketing and education. Health Education, 113, 392-406.

RUNDLE-THIELE, S., SCHUSTER, L., DIETRICH, T., RUSSELl-BENNETT, R., DRENNAN, J., LEO, C. \& CONNOR, J. P. 2015. Maintaining or changing a drinking behavior? GOKA's short-term outcomes. Journal of Business Research, 68, 21552163.

RUSSELL-BENNETT, R. \& GOLLEDGE, A. H. 2009. An investigation of cross-cultural differences in binge-drinking perceptions and behaviours.

SHERNOFF, D. J., CSIKSZENTMIHALYI, M., SCHNEIDER, B. \& SHERNOFF, E. S. 2003. Student engagement in high school classrooms from the perspective of flow theory. School Psychology Quarterly, 18, 158-176.

SHERNOFF, D. J., KELLY, S., TONKS, S. M., ANDERSON, B., CAVANAGH, R. F., SINHA, S. \& ABDI, B. 2016. Student engagement as a function of environmental complexity in high school classrooms. Learning and Instruction, 43, 52-60.

SHERNOFF, D. J., RUZEK, E. A. \& SINHA, S. 2017. The influence of the high school classroom environment on learning as mediated by student engagement. School Psychology International, 38, 201-218.

SPAETH, M., WEICHOLD, K., SILBEREISEN, R. K. \& WIESNER, M. 2010. Examining the differential effectiveness of a life skills program (IPSY) on alcohol use trajectories in early adolescence. Journal of Consulting and Clinical Psychology, 78, 334.

TEESSON, M., NEWTON, N. C., SLADE, T., CARRAGHER, N., BARRETT, E. L., CHAMPION, K. E., KELLY, E. V., NAIR, N. K., STAPINSKI, L. A. \& CONROD, P. J. 2017. Combined universal and selective prevention for adolescent alcohol use: a cluster randomized controlled trial. Psychological Medicine, 47, 1761-1770. 
TERLECKI, M. A., BUCKNER, J. D., LARIMER, M. E. \& COPELAND, A. L. 2015. Randomized controlled trial of brief alcohol screening and intervention for college students for heavy-drinking mandated and volunteer undergraduates: 12-month outcomes. Psychology of addictive behaviors, 29, 2.

TOBLER, N. S., ROONA, M. R., OCHSHORN, P., MARSHALL, D. G., STREKE, A. V. \& STACKPOLE, K. M. 2000. School-Based Adolescent Drug Prevention Programs: 1998 Meta-Analysis. Journal of Primary Prevention, 20, 275-336.

VASILAKI, E. I., HOSIER, S. G. \& COX, W. M. 2006. The efficacy of motivational interviewing as a brief intervention for excessive drinking: a meta-analytic review. Alcohol and Alcoholism, 41, 328-335.

VOGL, L. E., TEESSON, M., NEWTON, N. C. \& ANDREWS, G. 2012. Developing a school-based drug prevention program to overcome barriers to effective program implementation: The CLIMATE schools: Alcohol module. Open Journal of Preventive Medicine, 2, 410-422.

WHO 2006. AUDIT: The Alcohol Use Disorders Identification Test.

WHO 2014. Global status report on alcohol and health 2014. World Health Organisation.

WHO 2018. Global status report on alcohol and health 2018. World Health Organisation.

WILLIAMS, B. J., HAY, P. J. \& MACDONALD, D. 2011. The outsourcing of health, sport and physical educational work: A state of play. Physical Education \& Sport Pedagogy, 16, 399-415.

YIN, R. 2011. Qualitative Research from Start to Finish, New York., The Guilford Press,.

YIN, R. 2015. Qualitative Research from start to finish, New York, NY, The Guildford Press, Guildford Publications Inc. 